\title{
Análises físicas, composição centesimal e nutricional de minimilho (Zea mays, L.) orgânico de diferentes variedades ${ }^{1}$
}

\section{Physical analysis, and nutritional composition centesimal babycorn (Zea mays, L.) organic variety of different}

\author{
Adriana Santuzza de Oliveira Duarte de Lima ${ }^{2}$, Alana Rodrigues de Melo ${ }^{3}$, Lenice Freiman de Oliveira ${ }^{*}$, Valéria Ruschid \\ Tolentino ${ }^{5}$, Camila Silva Vaz Branco ${ }^{6}$
}

\begin{abstract}
Resumo: Atualmente os produtos orgânicos vêm roubando a cena dos produtos tradicionais, por serem saudáveis, livres de agrotóxicos e por gerarem menor impacto no meio ambiente. O minimilho (Zea mays, L.) também conhecido como "babycorn", uma espiga imatura ainda não fertilizada (espiguetas), é uma hortaliça, produto considerado fino que vem ganhando importância no mercado de conservas no Brasil. Esta pesquisa se propôs avaliar a qualidade de minimilho orgânico in natura de diferentes variedades e determinar a composição centesimal e nutricional.Utilizou-se como metodologias analíticas as determinações de rendimento, peso médio, diâmetro e comprimento das espiguetas, além de pH, sólidos solúveis, acidez titulável, umidade, cinzas, lipídeos, proteínas, carboidratos e valor energético total. Com os resultados obtidos concluiu-se que as variedades que apresentaram maior rendimento foram Pipoca (48,75\%), Eldorado (42,06\%)e Branco $(40,50 \%)$, sendo mais recomendadas para o beneficiamento e que o minimilho se trata de um produto de baixo valor calórico, podendo ser indicado em dietas hipocalóricas.
\end{abstract}

Palavras-chave: estudo, espiguetas, produção orgânica.

Abstract: Currently organic products come stealing the show from traditional products to be healthy, free of pesticides and generate less impact on the environment. The lithe corn (Zea mays L.) also known as " babycorn " an immature ear is not fertilized (spikelets), is a vegetable, thin product concerned that has gained importance in the market preserved in Brazil. This research aims to evaluate the quality of organic fresh baby corn in different varieties and determine the composition and nutritional. Used as analytical methodologies determinations yield, average weight, diameter and length of the spikelets , and $\mathrm{pH}$, soluble solids, titratable acidity, moisture, ash, lipids, proteins , carbohydrates and total energetic value . With these results it was concluded that the varieties of higher yield were Popcorn (48.75\%), Eldorado (42.06 \%) and White (40.50\%), and most recommended for improvement and that is babycorn is a product of low calorific value and can be displayed on a hypocaloric diet.

Keywords:study, spikelets, organic production.

\footnotetext{
*Autor para correspondência

Recebido para publicação em: 18/08/2015; Aprovado para publicação em: 20/12/2015.

${ }^{1}$ Pesquisa de Iniciação Cientifica, vinculada ao Projeto Pensa Rio financiado pela FAPERJ, Edital no $16 / 2009$.

${ }^{2}$ Bolsista de Iniciação Cientifica PROIC/UFRRJ e Discente do Curso de Economia Doméstica da UFRRJ, e-mail: adriana.santuzza@gmail.com

${ }^{3}$ Estagiária e Discente do Curso de Economia Doméstica da UFRRJ. e-mail: alanarodriguesab@yahoo.com.br

${ }^{4}$ Orientadora e Docente do Departamento de Economia Doméstica e Hotelaria - ICSA da UFRRJ, e-mail: freiman@ufrrj.br

${ }^{5}$ Co-orientadora e Docente do Departamento de Economia Doméstica e Hotelaria - ICSA da UFRRJ, e-mail: valeriart@ terra.com.br

${ }^{6}$ Assistente de Laboratório de Alimentação e Nutrição, DEDH/ICSA da UFRRJ, e-mail: camilavbranco@hotmail.com
} 


\section{INTRODUÇÃO}

O minimilho "babycorn" é o nome dado às espigas jovens (espiguetas), não polinizadas, no estágio de desenvolvimento inicial, antes mesmo da formação de grãos, de qualquer tipo de milho (PEREIRA FILHO, 2008). É uma hortaliça, produto considerado fino, apresenta textura crocante, sabor levemente adocicado e aparência delicada. Pode ser encontrado in natura ou na forma de conservas acidificadas, consumidas em pratos frios, como saladas, em sopas, em cozidos ou como aperitivos.

Atualmente, os produtos orgânicos vêm roubando a cena dos produtos tradicionais, por serem mais saudáveis, livres de agrotóxicos e por gerarem menor impacto no meio ambiente. Assim, o cultivo orgânico seguido do beneficiamento do minimilho no Brasil tem sido a aposta de alguns agricultores para o aumento do tempo de conservação dos produtos, além da geração de emprego e renda no campo. Estas possibilidades vêm se tornando gradualmente importantes, provocando um crescimento na sua área de cultivo (AEKATASANAWAN, 2001; MILES; ZENS, 2000). Mundialmente, o combate à pobreza e a emergência de assumir o acesso ao alimento como um direito humano, faz da concepção mais ampla do sistema orgânico de produção um compromisso inalienável, conforme pode ser compreendido na Lei 10.831 , que dispõe sobre o processo de produção, processamento, armazenamento, distribuição e comercialização e a proteção do meio ambiente (BRASIL, 2003a; BRASIL, 2009).

No Brasil, são produzidos 140 milhões de toneladas de alimentos por ano, é um dos maiores exportadores de produtos agrícolas do mundo e, ao mesmo tempo, têm-se milhões de excluídos, sem acesso ao alimento em quantidade e/ou qualidade. Para a população consumir equilibradamente os nutrientes de acordo com a IDR (Ingestão diária recomendada), são necessários estudar e disponibilizar mais dados sobre composição de alimentos. Pinho et al. (2003) determinaram a composição nutricional centesimal de oito cultivares de minimilhos produzidos de forma convencionale encontraram os seguintes resultados: umidade, 90,22 a 94,47\%; minerais (cinzas), 0,16 a 0,29\%; proteínas, 0,86 a 1,53\%; lipídeos (extrato etéreo), 0,09 a 0,19\%; fibra bruta (método não enzimático), 0,28 a 0,54\%; carboidratos (por diferença porcentual), 4,12 a 7,23\%. Também, foram determinados, em $100 \mathrm{~g}$ de minimilho, em média: $86 \mathrm{mg}$ de fósforo; 0,1 mg de ferro; $64 \mathrm{UA}$ de vitamina A; 0,05 $\mathrm{mg}$ de tiamina; 0,8 mg de riboflavina; $11 \mathrm{mg}$ de ácido ascórbico e $0,3 \mathrm{mg}$ de niacina.Ainda assim, as informações estatísticas sobre a produção e o consumo são limitadas porque muitos países produtores negligenciam ou não possuem essas informações. Segundo Pereira Filho, Gama e Cruz (1998), bem como Miles e Zenz (2000), o minimilho é muito consumido no continente asiático como hortaliça e representa uma atividade econômica significativa em vários continentes, em países tais como Tailândia, Sri Lanka, Taiwan, China, Zimbabwe, Zâmbia e Indonésia, bem como os da América Central, como Nicarágua, Costa Rica, Guatemala e Honduras, que são os exportadores mais conhecidos.

Esse é um produto promissor para o mercado externo e o interno, sobretudo porque, no Brasil, o produto industrializado é, em sua maioria, importado da Tailândia. Oaparecimento crescente do produto nas prateleiras dos supermercados mostra o potencial do mercado consumidor brasileiro, indicando também uma abertura para o mercado externo, principalmente o americano e o europeu.

No Brasil, diferentes cultivares de milho têm sido avaliadas com o intuito de identificar aquelas mais adaptadas às condições tropicais (ALMEIDA et al., 2005; CARVALHO; PINHO; PEREIRA FILHO, 2002; PEREIRA FILHO; GAMA; CRUZ, 1998; PINHO et al., 2003; RODRIGUES; SILVA; SEIZO, 2004). Segundo Carvalho, Pinho e Pereira Filho (2002) o peso de espiguetas comerciais é considerado a característica mais importante para a produção de minimilho. Estes pesquisadores avaliaram o desempenho de oito cultivares de milho em diferentes épocas de semeadura, associado ao efeito do despendoamento das plantas na produção de minimilho. Foi avaliado o peso das espiguetas empalhadas, o peso de espiguetas comerciais e o rendimento de espiguetas comerciais. Entre as cultivares avaliadas, a DKB 929 se destacou, apresentando o melhor desempenho para peso de espiguetas empalhadas e peso de espiguetas comerciais, independente da época de semeadura. $\mathrm{O}$ despendoamento proporcionou aumento na produtividade de espiguetas comerciais, independente da época de semeadura. Em seguida, observaram-se bons desempenhos das cultivares de milho doce e pipoca, ressaltando serem estas as mais utilizadas para a produção de minimilho, no Brasil.

Durante o armazenamento das espiguetas, a redução no peso devido às perdas de água na evaporação e respiração chega, aproximadamente, a $6,8 \%$ por três dias de armazenagem, reduzindo também a qualidade, devido à maturação do sabugo (LEKAGUL et al., 1981). Assim, as propriedades agrícolas que desejarem produzir minimilho devem estar próximas das instalações de processamento, com o intuito de evitar problemas com a fermentação, perda do material e reduzir o custo com o transporte. Outra possibilidade é a comercialização na forma de conservas, geralmente enlatadas ou em vidros específicos para essa finalidade.

A aparência da espigueta é de suma importância para o consumidor, razão porque é comum na produção de conservas o seu envase em vidro transparente para permitir que o consumidor aprecie características como coloração, formato, tamanho e diâmetro. As espiguetas devem apresentar os seguintes padrões comerciais: coloração de branco-pérola a amarelo-claro; forma cilíndrica com ovários pequenos em fileiras uniformes e simétricas; diâmetro de 10 a $18 \mathrm{~mm}$ e comprimento de 40 a $120 \mathrm{~mm}$. A produção de minimilho no Brasil, ainda é inexpressiva, não existe relato de exportação, ao contrário, ainda se importa esse tipo de conserva para o abastecimento de um mercado interno em franca expansão (AEKATASANAWAN, 2001; MILES; ZENZ, 2000; PEREIRA FILHO; CRUZ, 2001; PEREIRA FILHO; GAMA; CRUZ, 1998; PINHO et al., 2003; RODRIGUES; SILVA; SEIZO, 2004).

O minimilho, a semelhança do que já ocorre com o milho verde, se constitui em alternativa para a agricultura familiar, que poderá comercializá-lo in natura ou na forma de conservas, disponibilizando, com isso, um novo produto para o consumidor que aprecia o milho, bem como agrega valor à produção. E para adequar aos princípios de uma tecnologia limpa, após a colheita, a palhada da cultura do minimilho poderá ser utilizada para ensilagem (CRUZ et al. 2006; MARIN, 2007). Para os produtores de hortigranjeiros pode 
ser uma fonte de renda compensadora em virtude do aproveitamento da parte vegetativa que pode ser usada como feno ou silagem de alta qualidade (STORCK; LOVATO; COMASSETTO, 1984).

Assim, esta pesquisa se propôs avaliar a qualidade de minimilho orgânico in natura de diferentes variedades, através de análises físicas e da composição centesimal e nutricional com vistas à produção de conservas.

\section{MATERIAL E MÉTODOS}

Foram analisadas 6 (seis) diferentes variedades de minimilho, sendo elas: Pipoca, Super Doce, Doce Cristal, Eldorado, Catetinho e Branco, todas obtidas sob manejo orgânico e produzidas pela Fazendinha - Embrapa Agrobiologia - Seropédica/RJ. As amostras foram transportadas para o Laboratório de Beneficiamento de Alimentos do Departamento de Economia Doméstica e Hotelaria do Instituto de Ciências Sociais Aplicadas da UFRRJ, Seropédica/RJ, onde foram estudadas.

Para verificação das características físicas das amostras de minimilho destinadas ao consumo, estas foram separadas em lotes, pesadas em balança semi-analíticada Marca Elgin, Modelo DP-15 Plus para obtenção do peso bruto (g), que é representado pelo peso das espiguetas com palha. $\mathrm{Na}$ sequência, todas as amostras foram despalhadas e pesadas para obtenção do peso líquido (g), em seguida calculado o rendimento (\%).As espiguetas de cada variedade de minimilho passaram por medição quanto ao comprimento (cm) e o diâmetro (cm).

Para avaliação das propriedades físico-químicas, amostras contendo dez unidades de minimilho in natura de diferentes variedades foram trituradas em liquidificador doméstico para obtenção de polpa homogênea e imediatamente, usada para determinar a composição centesimal. As análises foram feitas em triplicata.

Sólidos solúveis (SS): determinado diretamente na polpa de minimilho, por refratometria (IAL, 2008), os resultados foram expressos em ${ }^{\circ}$ Brix.
pH: determinado com pHmetro, após calibração com solução tampão pH 4,0 e 7,0, segundo o método 981.12 da AOAC (2005).

Acidez titulável (AT): determinada por titulação com hidróxido de sódio $(\mathrm{NaOH})$ 0,1N, de acordo com o método 942.15 da AOAC (2005), e o resultado expresso em porcentagem de ácido cítrico.

Umidade: determinada em estufa a $105{ }^{\circ} \mathrm{C}$ até obter peso constante, de acordo com o procedimento indicado pelo IAL (2008).

Cinzas: determinadas por incineração em mufla a $550{ }^{\circ} \mathrm{C}$ até obter peso constante, conforme método referido no IAL (2008).

Proteínas: calculadas pelo teor de nitrogênio total, determinado pelo método de Kjeldahl, empregando 6,25 como fator de conversão, seguindo a AOAC (2005).

Lipídeos: determinado em aparelho extrator de Soxhlet, usando éter de petróleo como solvente, seguindo metodologia descrita pelo IAL (2008).

Carboidratos: foram avaliados através de cálculo teórico por diferença de $100 \%$ incluindo fibra bruta.

Valor energético total (VET): foi calculado a partir dos fatores de conversões tradicionais de $4 \mathrm{Kcal} / \mathrm{g}$ para carboidratos e proteínas e $9 \mathrm{Kcal} / \mathrm{g}$ para o lipídeo (BRASIL, 2003b).

Todas as determinações foram efetuadas em triplicata e os resultados submetidos à análise estatística descritiva pelo Programa Statistic5.0 e os resultados foram expressos, pela média \pm incerteza (IC).

\section{RESULTADOS E DISCUSSÃO}

As respostas às características físicas do minimilho estão demonstradas na Tabela 1. Estes dados contribuíram para a avaliação da aparência e formato dessas variedades, já que é de suma importância para o consumidor aparência geral do produto a ser consumido.

Tabela 1. Resultados das análises físicas de variedades de minimilho produzidos em sistema de cultivo orgânico na Fazendinha - Embrapa Agrobiologia - Seropédica/RJ*.

\begin{tabular}{lcccc}
\hline Variedades & $\begin{array}{c}\text { Rendimento } \\
(\boldsymbol{\%})\end{array}$ & $\begin{array}{c}\text { Peso das espiguetas } \\
(\mathbf{g})\end{array}$ & $\begin{array}{c}\text { Diâmetro } \\
(\mathbf{c m})\end{array}$ & $\begin{array}{c}\text { Comprimento } \\
(\mathbf{c m})\end{array}$ \\
\hline Pipoca & $48,75 \%$ & $15,20( \pm 1,75)$ & $1,36( \pm 0,16)$ & $10,40( \pm 1,52)$ \\
Super doce & $23,72 \%$ & $14,20( \pm 1,93)$ & $1,26( \pm 0,20)$ & $11,40( \pm 0,72)$ \\
Doce cristal & $24,19 \%$ & $14,50( \pm 4,27)$ & $1,37( \pm 0,20)$ & $10,20( \pm 1,76)$ \\
Eldorado & $42,06 \%$ & $15,00( \pm 3,64)$ & $1,42( \pm 0,16)$ & $10,30( \pm 1,44)$ \\
Catetinho & $30,41 \%$ & $14,40( \pm 3,38)$ & $1,43( \pm 0,16)$ & $10,10( \pm 2,06)$ \\
Branco & $40,50 \%$ & $14,50( \pm 2,45)$ & $1,47( \pm 0,10)$ & $12,00( \pm 0,80)$ \\
\hline
\end{tabular}

*Os valores encontrados referem-se à média da amostragem de 10 minimilhos.

As unidades experimentais foram constituídas de 10 (dez) espiguetas de cada variedade, selecionadas após o despalhamento, pesagem e medição individual.

Os rendimentos médios dos minimilhos sem palha em relação à matéria-prima com palha foram de: $23,72 \%$ na variedade Super Doce, 24,19\% na variedade Doce Cristal, $30,41 \%$ na variedade Catetinho, $40,50 \%$ na variedade Branco, $42,06 \%$ na variedade Eldorado e de $48,75 \%$ na variedade Pipoca, conforme Tabela 1. Considerando a importância do rendimento como um item exigido pela indústria para o processamento na forma de conservas, os cultivares das variedades Pipoca $(48,75 \%)$, Eldorado $(42,06 \%)$ e Branco $(40,50 \%)$ foram mais recomendados para o cultivo e beneficiamento, por apresentarem maiores rendimentos em relação às outras variedades. Os dados de peso médio das espiguetas e de rendimento encontrados foram superiores aos estudados por Raupp et al., (2008), que encontraram peso que variou entre 8,7 e $10,9 \mathrm{~g}$ e rendimento entre 20,4 e $27,5 \%$ e aos de Junior et al. (2009).que encontraram peso que variou de 6,3 a $12,1 \mathrm{~g}$ e o rendimento considerado inadequado para a 
comercialização. Observa-se que nenhuma das variedades estudadas na presente pesquisa encontra-se reportada nos trabalhos citados e este fator pode ser atribuído às diferenças de resultados.

Todas as variedades do presente estudo apresentaram coloração amarelo-claro, formatos cilíndricos, diâmetros e comprimentos médios de 1,0 a $1,8 \mathrm{~cm}$ e 5,0 a $12,0 \mathrm{~cm}$, respectivamente. De acordo com Pereira Filho e Cruz (2001) os padrões comerciais exigem formato cilíndrico, coloração variando de branco-pérola ao amarelo-claro, de 10 a $18 \mathrm{~mm}$ de diâmetro e de 40 a $120 \mathrm{~mm}$ de comprimento. Destas características, a coloração e o formato são pouco influenciados pelo ambiente.

Importante lembrar que o diâmetro da espigueta é uma característica indicadora fitotécnica de qualidade de minimilho, visto que maiores diâmetros de espigueta relaciona-se diretamente em maior desenvolvimento do sabugo, tendo consequentemente um maior acúmulo de matéria seca, aumento da textura e redução de sua palatabilidade, assim como, diâmetros inferiores resultam em perdas pela fragilidade da matéria-prima, que se rompe facilmente, ocasionando depreciação da qualidade visual do produto e redução do rendimento final de minimilho (JUNIOR et al., 2009).Alguns autores afirmaram que estas características são consideradas pelos consumidores como atributos de qualidade (AEKATASANAWAN, 2001; MILES; ZENZ, 2000; PEREIRA FILHO; CRUZ, 2001; PEREIRA FILHO; GAMA; CRUZ, 1998; PINHO et al., 2003; RODRIGUES; SILVA; SEIZO, 2004).

Os resultados das análises físico-químicas das variedades de minimilho são apresentadas na Tabela $\underline{2}$. Observou-se que as diferentes variedades apresentaram teores de umidade de 83,02 a 92,10\%; pH de 5,54 a 5,83\%; sólidos solúveis ( BRIX) entre 3 e 6\%;acidez titulável (AT) entre 0,27 a $0,70 \%$; cinzas de 0,32 a $0,70 \%$; lipídeos de 0,83 a $1,14 \%$; proteínas de 0,41 a $0,51 \%$; carboidratos de 6,07 a $13,84 \%$ e VCT de 35,15 a $67,62 \%$ Kcal. Essa variação na composição química, bem como a diferença aos estudos de outros autores, é atribuída às diferenças entre espécies e cultivares (KWIATKOWSKI; CLEMENTE, 2007).

Tabela 2-Resultados das análises físico-químicas e nutricional de minimilho orgânico de diferentes variedades (Fazendinha Embrapa Agrobiologia - Seropédica/RJ), 2012.

\begin{tabular}{lcccccc}
\hline \multirow{2}{*}{$\begin{array}{l}\text { Consti- } \\
\text { tuintes }\end{array}$} & \multicolumn{5}{c}{ Variedades de minimilho in natura } \\
\cline { 2 - 6 } & Pipoca & Super Doce & Doce Cristal & Eldorado & Cate-tinho & Branco \\
\hline pH & $5,75(0,02)$ & $5,83(0,02)$ & $5,54(0,01)$ & $5,76(0,02)$ & $5,61(0,02)$ & $5,77(0,02)$ \\
AT $(\%)$ & $0,33(0,02)$ & $0,70(0,02)$ & $0,31(0,01)$ & $0,29(0,02)$ & $0,27(0,01)$ & $0,37(0,02)$ \\
SS $\left({ }^{\circ}\right.$ BRIX) & $4,00(0,00)$ & $3,00(0,00)$ & $4,50(0,29)$ & $5,00(0,00)$ & $4,00(0,00)$ & $6,00(0,00)$ \\
Umidade $(\%)$ & $88,54(0,06)$ & $92,10(0,07)$ & $89,40(0,05)$ & $87,68(0,04)$ & $83,02(0,04)$ & $87,82(0,06)$ \\
Cinzas $(\%)$ & $0,34(0,02)$ & $0,38(0,01)$ & $0,37(0,01)$ & $0,32(0,02)$ & $0,57(0,02)$ & $0,70(0,01)$ \\
Proteínas ${ }^{3}(\%)$ & $0,48(0,02)$ & $0,48(0,02)$ & $0,41(0,02)$ & $0,51(0,03)$ & $0,50(0,04)$ & $0,49(0,02)$ \\
Lipídeos $(\%)$ & $0,83(0,01)$ & $0,99(0,08)$ & $0,97(0,07)$ & $0,92(0,04)$ & $1,14(0,04)$ & $1,13(0,02)$ \\
Carboidratos $(\%)$ & $9,66(0,11)$ & $6,07(0,11)$ & $8,95(0,11)$ & $10,60(0,11)$ & $13,84(0,04)$ & $9,73(0,07)$ \\
VET (calorias) & $48,04(0,16)$ & $35,15(0,22)$ & $46,19(0,21)$ & $52,74(0,15)$ & $67,62(0,23)$ & $51,07(0,32)$ \\
\hline
\end{tabular}

${ }^{1}$ Os valores das constituintes encontrados referem-se à média de três repetições; $($ ) = desvio padrão.

$\mathrm{O}$ pH do presente estudo apresentou uniformidade de valores, ou seja, variação de 5,5 a 5,8 , comprovando que o minimilho é um alimento pouco ácido. Tal afirmação é comprovada pelos valores de acidez titulável que ficaram entre 0,20 e $0,70 \%$. Sabe-se que opH é um fator importante para a conservação e o processamento dos alimentos, e a faixa desejável é de $\mathrm{pH}$ igual ou inferior a 4,5 para impedir a proliferação de microrganismos patogênicos, especificamente do Clostridium botulinum, que em condições favoráveis pode resultar em óbito para o consumidor que ingerir tal produto alimentício (BRIMELOW; VADEHRA, 1992; FRANCO; LANDGRAF, 1996). Além disso, valores de pH acima de 4,5, como é o caso do minimilho do presente estudo, requerem períodos mais longos de tratamento térmico em um processamento, ocasionando maior consumo de energia e consequentemente maior custo de produção. Assim, caso o minimilho seja processado na forma de conservas, para resolver este impasse, deve-se utilizar líquidos de cobertura ácidos suficientemente para que após o equilíbrio osmótico, este permaneça com pH final igual ou abaixo de 4,5 (RAUPP et al., 2008).

Quanto ao teor de sólidos solúveis (SS), se refere à porcentagem, em peso, de sólidos que se encontram dissolvidos no alimento. São registrados em ${ }^{\circ}$ Brix e no caso de frutas e hortaliças refere-se aos açúcares e/ou sais, e têm tendência de exibir maior concentração com a evolução da maturação, devido ao processo de biossíntese ou ainda pela degradação de polissacarídeos (NYALALA; WAINWRIGHT, 1998). Neste estudo, os SS variaram entre 3,0 e 6,0 ${ }^{\circ}$ Brix e foram superiores aos Raupp et al. (2008), que encontraram de 1,9 a 2,2 e próximos aos de Reis et al. (2005) que foram em torno de $2,9^{\circ}$ Brix.

Quanto às variações observadas deve-se levar em conta que em se tratando de alimentos de origem vegetal, essas diferenças são inerentes à variedade, às condições de cultivo, de clima e de fertilidade do solo (MESQUITA et al. 2007).

Sabe-se que a umidade do alimento é um parâmetro importante, pois está relacionada com a maior ou menor concentração de componentes solúveis, bem como a fragilidade física do fruto. Neste estudo, os teores de umidade encontrados nas seis variedades oscilaram entre 83 e $92 \%$, valores próximos aos encontrados por Raupp et al., (2008) que avaliaram quatro variedades de minimilho (90,3 a 90,8\%) e aos de Yodpet (1979), que encontrou teor médio de $89 \%$.

A quantidade de cinzas variou de 0,32 a $0,70 \%$ e indicou a concentração total de minerais nas amostras de minimilho orgânicas. Estes valores foram superiores aos encontrados por Pinho et al. (2003)em diferentes variedades de minimilho $(0,16$ a $0,29 \%)$ obtidos em cultivo convencional. Tal diferença poderia ser atribuída ao sistema de cultivo orgânico, já que algumas pesquisas afirmam que a produção orgânica influencia positivamente na concentração de minerais dos alimentos (LAIRON, 1985; SCHUPHAN, 1974; SMITH, 1993; AUBERT, 1981). No entanto, apesar dos dados do 
presente estudo indicarem superioridade do orgânico sobre o convencional, não é suficiente para tomada de posição. Desse modo, recomenda-se que maior número de pesquisas seja desenvolvido, analisando, pormenorizadamente, os aspectos qualitativos e ainda examinando ampla gama de produtos.

Em relação ao conteúdo de proteínas, os minimilhos das diferentes variedades analisados apresentaram valores que variaram de 0,41 a 0,50\%, valores inferiores aos encontrados por Raupp et al. em 2008 (1,2 a 1,56\%) e ligeiramente superiores aos de Pinho et al. em $2003 \quad(0,16$ e 0,29\%).Importante o conhecimento do teor de proteínas dos alimentos, porque este nutriente tem sido uma das principais causas de desnutrição de crianças. E as proteínas são essenciais para manter a estrutura e funcionamento do organismo vivo e podem ter diferentes propriedades e funções, são elas: formação de ossos e dentes, contração muscular, produção de anticorpos, entre outras. Comparando o minimilho com o milho comum, após 25 dias da polinização, Machado (1988) encontrou valores entre 11,3 e $13,3 \mathrm{~g}$ de proteínas/100 g de milho, o que significa de 11 a $13 \%$.Provavelmente, essa diferença no teor de proteína do minimilho deve-se à sua imaturidade, visto que a fertilização, responsável pela translocação de nitrogênio, ainda não ocorrera.

Em relação ao conteúdo de lipídeos, como a maioria das hortaliças (chuchu, batata inglesa e cenoura), o minimilho também não é fonte representativa deste nutriente (MENDEZ et al., 2001; INSTITUTE OF NUTRITION, 1999). As variedades de minimilho orgânicos estudados apresentaram valores de 0,83 a 1,14\% de lipídeos. Pinho et al., (2003) encontraram valores inferiores, entre 0,16 e $0,19 \%$ de lipídeos. Os autores afirmam que esses valores são baixos porque antes da fertilização a taxa de translocação de nutrientes para a espiga ainda é muito reduzida, quando comparada com uma espiga cujos óvulos já foram fertilizados. Por isso, em milho comum, após 25 dias da polinização, o valor encontrado por Machado (1988) foi de $4,8 \mathrm{~g} / 100 \mathrm{~g}$.

Os carboidratos são os componentes mais importantes nos cereais, formando $83 \%$ da matéria seca total das sementes de milho comum. No caso do minimilho, as espigas são imaturas, sendo os níveis de carboidratos menores. No presente estudo, variaram de 6,07\% na variedade Super doce a $13,84 \%$ na variedade Catetinho. A literatura mostra valores próximos, como de 4,12 a 7,23\% e 8,20 para Pinho et al. (2003) e Yodpet (1979), respectivamente. Assim como outros nutrientes, os carboidratos podem variar em sua composição física e química em função da cultivar e das condições edafo-climáticas. Consequentemente, o valor calórico total encontrado nas seis variedades foi considerado baixo, onde a variedade Super doce apresentou 35,15 Kcal e foi a menos calórica, do contrário, a Catetinho apresentou $67,62 \mathrm{kcal}$. Assim, este trabalho corrobora com a literatura, na afirmação de que o minimilho é um produto de baixa caloria, devendo ser inserido nas dietas especiais hipocalóricas (STERTZ, 2004). Franco (2005) mostra que o milho verde cru e o milho maduro possuem 325,6 e 362,7 kcal, respectivamente.

Com estes resultados, é possível observar que o minimilho orgânico tem bom potencial para ser processado e comercializado na forma de conservas acidificadas, pois tem vantagem de ser uma hortaliça de baixo valor calórico. Estes dados corroboram com os obtidos por Raupp et al. (2004), na confirmação do minimilho como um alimento de baixo valor calórico, igualmente o palmito e outras conservas vegetais, que deve ter seu consumo estimulado na alimentação humana.

\section{CONCLUSÕES}

Dentre as variedades estudadas, recomenda-se investir no cultivo de Pipoca, Eldorado e Catetinho por apresentarem maior rendimento (sem palha) em relação às outras variedades;

Todas as variedades estudadas apresentaram boa qualidade em relação aos aspectos físicos (formato, coloração, peso, comprimento e diâmetro), importantes para o processamento em conservas;

A composição centesimal não demonstrou grande variabilidade entre as amostras e apresentaram-se similares aos comumente relatados na literatura, mas demonstrou ser um alimento de baixo valor calórico, por isso pode ser uma importante alternativa em dietas hipocalóricas em substituição ao consumo de milho verde ou derivados de milho,

É importante que se invista em pesquisa científica na área da agricultura orgânica, no sentido de aumentar o rendimento das matérias-primas para que o pequeno agricultor comercialize sua produção reduzindo a perdas póscolheita, assim como possa processar os excedentes de produção, agregando valor ao produto final, desde que utilize técnicas que mantenham as características de alimento orgânico.

As pesquisas na produção orgânica de minimilho estão em fase inicial e muito deve ser feito, principalmente de forma participativa, com troca de experiências entre pesquisadores, produtores e extensionistas. Entretanto, podese esperar, em pouco tempo, uma grande evolução de sua produção dentro de princípios agroecológicos.

\section{REFERÊNCIAS BIBLIOGRÁFICAS}

AEKATASANAWAN, C. Baby corn. In: HALLAUER, A.R. Specialty corns. v.2, 2 ed. Lowa: CRC Press. cap.9, p.275-292. 2001.

ALMEIDA, I.P.C; SILVA, P.S.L.; NEGREIROS, M.Z.; BARBOSA, Z. Baby corn, green ear, and grain yield of corn cultivars. HorticulturaBrasileira, v.23, n.4, p.960964, 2005.

ASSOCIATION OF OFFICIAL ANALYTICAL CHEMISTS (AOAC).Official Methods of analysis of Association of Official Chemists.13 ed. Washington. 2005, 620p.

AUBERT, C. Palestra: Engenheiro Agrônomo Claude Aubert. In: ENCONTRO BRASILEIRO DE AGRICULTURA ALTERNATIVA, 1, Curitiba, 1981. Anais... Curitiba: Federação dos Eng. Agrônomos do Brasil/Associação dos Eng. Agrônomos do Paraná, 1981, p.161-190.

BRASIL. Lei nº10. 831, de 23 de dezembro de 2003. Dispõe sobre a agricultura orgânica e dá outras providências. Disponível em <http://www.planalto.gov.br/ccivil_03/Leis/2003/L10.8 31.htm>. Acesso em 22/10/2011. 
BRASIL. Ministério da Saúde. Agência Nacional de Vigilância Sanitária. Resolução RDC n.359, de 23 de dezembro de 2003. Regulamento técnico de porções de alimentos embalados para fins de rotulagem nutricional. Diário Oficial da União, 26 de dezembro de 2003b.

BRASIL. Ministério da Agricultura Pecuária e do Abastecimento. Ministério da Saúde. Instrução Normativa Conjunta $n^{\circ} 18$, de 28 de maio de 2009. Aprova o regulamento técnico para o processamento, armazenamento e transporte de produtos orgânicos. Diário Oficial da União, Brasília, DF, Seção 1, 2011. p.15

BRIMELOW, C.; VADEHRA, D. Refrigeración. In: ARTHEY, D.; DENNIS, C. Procesado de hortalizas. Zaragoza (Espanha): Editorial Acribia, 1992. p.139-173.

CARVALHO, G.S.; PINHO, R.G.V.; PEREIRA FILHO, I.A. Efeito do tipo de cultivar, despendoamento das plantas e da época de semeadura na produção de minimilho. Revista Brasileira de milho e sorgo, v.1, n.3, p. 47-58. 2002.

CRUZ,J.C., KONZEN, E.A., MARRIEL, I.E., CRUZ, I., DUARTE, J.O.; OLIVEIRA, M.F., ALVARENGA, R. C. Produção de milho orgânico na agricultura familiar, Circular técnica 81, Embrapa milho e Sorgo, Sete Lagoas - MG, 1ed., 2006. 17p.

FRANCO, B.D.G.M.; LANDGRAF, M. Microrganismos patogênicos de importância em alimentos. In: FRANCO, B.D.G.M.; LANDGRAF, M. Microbiologia dos alimentos. São Paulo: Editora Atheneu. p.33-41, 1996.

FRANCO, G. Tabela de composição química dos alimentos, 9.ed. São Paulo: Atheneu, 2005. 229p.

IAL - INSTITUTO ADOLFO LUTZ. Normas Analíticas do Instituto Adolfo Lutz: métodos químicos e físicos para análise de alimentos. São Paulo: IAL. 2008. 533p.

INSTITUTE OF NUTRITION. Thai food composition tables. 1999. Available at: < http://agsyst.wsu.edu >. Access: 12 January 2012.

JUNIOR, G.B.S.; PAULI, D.A.; SANTOS, F.S.; FERREIRA, F.R.A. Avaliação de híbridos de milho-pipoca para produção de minimilho, In: VI ENCONTRO INTERNACIONAL DE PRODUÇÃO CIENTÍFICA CESUMAR, 2009, Paraná. Anais... Paraná: Cesumar, 2009.

KWIATKOWSKI, A., CLEMENTE, E. Características do milho doce (Zeamays 1.) para industrialização, Revista Brasileira de Tecnologia Agroindustrial, Ponta Grossa, v.1, n. 2 p. 93-103, 2007.

LAIRON, D. Efecto de lãs fertilizaciones orgânicas y minerales sobre el valor nutritivo de lãs prodicciones agrícolas, In: CONGRESSO CIENTÍFICO EUROPEU DE AGRICULTURA BIOLÓGICA, Madrid, 1985. Ponencias y Comunicaciones. Madrid: IFOAM/Association Vida sana, 1985. p.254-271.

LEKAGUL, T.; PERNMAMKHONG, S.; CHUTKAEW, C.; BENJASIL,V. Field corn variety for young ear corn production.National Corn and Sorghum Program Annual Report, Bangkok, v.13, p. 201-205, 1981.

MACHADO, M.C.M. S. T. Estudo da composição química, características agronômicas e sensoriais de uma nova cultivar de milho, com endosperma triplo mutante sugary-opaque 2-waxy. 1988. 114 f. Dissertação (Mestrado em Ciência dos Alimentos) - Universidade Estadual de Campinas, Campinas, 1988.

MARIN, R. Duas safras em sete meses. Revista da lar: Medianeira, ano I, n. 3, p. 18-21, abr./mai., 2007.

MENDEZ, M.H.M.; DERIVI, S.C.N.; RODRIQUES, M.C.R.; FERNANDES, M.L.Tabela de composição de alimentos. Niterói: EDUFF, 2001. 67p.

MESQUiTA, F. R., CORRÊA, A. D., ABREU, C. M. P. , LIMA, R. A. Z., ABREU, A. F. B., Linhagens de feijão (Phaseolusvulgaris 1.): composição química e digestibilidade protéica. Ciência agrotecnologia. Lavras, v. 31, n. 4, p. 1114-1121, jul./ago., 2007.

MILES, C.A.; ZENZ, L. Baby corn. In: Farming West of the Cascades. Washington, D.C.: Washington State University. 8p. 2000. Available in : http : //cru.cahe.wsu.edu/cepublications/pnw0532/pnw0532.pd f ). Access: 22/10/11 .

NYALALA, S.P.O.; WAINWRIGHT, H.The self life or tomato cultivars at different storage temperatures.Tropical Science, v.38, p.151-154, 1998.

PEREIRA FILHO, I.A. Minimilho: cultivo e processamento. Manual técnico, Sete Lagoas: Embrapa Milho e Sorgo, 2008. 244 p.

PEREIRA FILHO, I.A.; CRUZ, J.C. Manejo cultural do minimilho. Manual técnico, Sete Lagoas-MG: Empresa Brasileira de Pesquisa Agropecuária - Centro Nacional de Pesquisa de Milho e Sorgo, 1ed.,2001, 4p.

PEREIRA FILHO, I.A.; GAMA, E.E.G.; CRUZ, J.C. Minimilho: efeito de densidade de plantio e cultivares na produção e em algumas características da planta do milho. Comunicado Técnico da Empresa Brasileira de Pesquisa Agropecuária - Centro Nacional de Pesquisa de Milho e Sorgo, n.23, p.1-6. 1998.

PINHO, R.G.V., CARVALHO, G.S., RODRIGUES, V.N., PEREIRA, J. Características físicas e químicas de cultivares de milho para produção de minimilho, Ciência agrotecnologia, Lavras, nov./dec., v.27, n.6, p.14191425, 2003. 
QUEIROZ, V.A.V; FILHO, I.A.P. Processo de produção de conserva caseira de minimilho. Sete Lagoas: Embrapa Milho e Sorgo, 2010. p.6.

RAUPP, D.S.; ALMEIDA, F.C.C.; STARON, E.A.; VALLE, J.; BORSATO, A.V.; SANTOS, A.F. Conservas de palmito de pupunha em diferentes salmouras - avaliação senrorial. Publicatio,v.10, n.1, p. 27-33. 2004.

RAUPP, D.S.; GARDINGO, J.R.; MORENO, L.R.; HOFFMAN, J.P.M.; MATIELLO, R.R.; BORSATO, A.V. Minimilho em conserva: avaliação de híbridos. Revista Acta Amazônica, v. 38, n.3, p. 509-16, 2008.

RODRIGUES, L.R.F.; SILVA, N.A.M.; SEIZO, E. Avaliação de sete famílias $\mathrm{S} 2$ prolificas de minimilho para a produção de híbridos. Bragantia, v.63, n.1, p.3138, 2004.

SCHUPHAN, W. Nutritive value of crops as influenced by organic and inorganic fertilizer treatment.QualitasPlantarum: plant foods for human nutrition, v.23, n.4, p.333-58, 1974.
SMITH, B.L. Organic foods vs. supermarked foods: elements levels. Jornal de Nutrição Aplicada, v. 45, n. 1, p.35-39, 1993.

STERTZ, S.C. Qualidade de hortícolas convencionais, orgânicas e hidropônicas na Região Metropolitana de Curitiba - Paraná. 2004. 260f. Tese (Doutorado em Tecnologia) - Universidade Federal do Paraná, Curitiba, 2004.

STORCK, L.; LOVATO, C.; COMASSETTO, V. Avaliação do rendimento e outras características agronômicas de cultivares de milho doce. Revista Científica Ciência Rural, v.14, p.153-160, 1984.

YODPET, C. Studies on sweet corn as potential young cob corn (Zea mays, L). 1979. Thesis (Doctor) - University of the Philippines, Los Banos, 1979.

VON SPERLING, Marcos /Introdução a qualidade das águas e ao tratamento de esgotos/ Marcos Von Sperling. - 3. Ed. - Belo Horizonte: Departamento de Engenharia Sanitária e Ambiental; Universidade Federal de Minas Gerais; 2005. 